\title{
Two-stage model for order discrimination
}

\author{
- PIOTR JAŚKOWSKI \\ Medical Academy, Poznañ, Poland
}

\begin{abstract}
Ulrich (1987), exploring the shapes of psychometric functions obtained in the ternary-response paradigm, indicated several inconsistencies between observed and predicted relationships providing evidence against most popular models of temporal-order judgment. In this paper, a new model is presented. It assumes that there are two mechanisms involved in the order discrimination task: one is responsible for the recognition of whether or not the stimuli are successive, and the second is able to determine their order. The model was tested using Allan's (1975a, 1975b) and Ulrich's (1987) data; the model predictions were found to be consistent with the experimental results.
\end{abstract}

When two stimuli are presented to an observer simultaneously or in close temporal proximity, their subjective order is sometimes different than the actual one. Although the problem is very old, only during the last 3 decades have the majority of temporal-order judgment (TOJ) models been proposed. The most popular are three models: attention-switching, perceptual-moment, and triggered-moment models (for a review, see Sternberg \& Knoll, 1973, and Ulrich, 1987).

Recently, Ulrich (1987) pointed out that all these models are particular cases of a general model, which he called the general threshold model. According to this model, two sensory messages elicited by two stimuli reach a point in the brain at different times. The difference results from the latency dispersion and the stimulus onset asynchrony. The subject is able to determine the order only if the difference is larger than a threshold value that is considered to be a random variable. When the arrival time difference is smaller than this value, the subject has no information about the order. The three models mentioned above differ in respect to the particular assumptions concerning the probability distributions of threshold values.

Typically, in the TOJ experiment, the subject is asked to judge which of the two stimuli, say $S_{\mathrm{x}}$ and $S_{\mathrm{y}}$, was presented first. Usually, two response categories are permitted: " $S_{\mathrm{x}}$ before $S_{\mathrm{y}}$ ", (response: $x y$ ) and " $S_{\mathrm{y}}$ before $S_{\mathrm{x}}$ ", (response: $y x$ ). In their experiments, Allan (1975a, 1975b) and Ulrich (1987) introduced the ternary-response paradigm, which allows three categories of the subject's response: the additional category is "they were simultaneous" (response: si). On the basis of the subject's responses, three probabilities can be generated, $\operatorname{Pr}\{y x \mid d\}$,

Correspondence should be addressed to Piotr Jaskowski, Department of Biophysics, Medical Academy, Fredry 10, 61-701 Poznań, Poland.
$\operatorname{Pr}\{x y \mid d\}, \operatorname{Pr}\{s i \mid d\}$, as a function of $d$, where $d$ is the time difference between presentation of $S_{\mathrm{x}}$ and $S_{\mathrm{y}}$.

It was shown (Ulrich, 1987) that, in the framework of the general threshold model, $Y_{\mathrm{L}}(d):=1-\operatorname{Pr}\{y x \mid d\}$ and $Y_{\mathbf{R}}(d):=\operatorname{Pr}\{x y \mid d\}$ can be considered as cumulative distribution functions of the two random variables $\mathbf{D}_{\mathbf{L}}:=$ $\mathbf{L}_{\mathbf{x}}-\mathbf{L}_{\mathbf{y}}+\mathbf{C}_{\mathrm{xy}}$ and $\mathbf{D}_{\mathbf{R}}:=\mathbf{L}_{\mathbf{x}}-\mathbf{L}_{\mathbf{y}}-\mathbf{C}_{\mathbf{y x}}$, where $\mathbf{L}_{\mathrm{x}}$ and $\mathbf{L}_{\mathbf{y}}$ are latencies of $S_{\mathrm{x}}$ and $S_{\mathrm{y}}$, respectively, and $\mathrm{C}_{\mathrm{xy}}$ and $\mathbf{C}_{\mathrm{yx}}$ are the threshold values (indices are added to the threshold values to indicate that thresholds may depend on the order of arrivals of sensory messages at the central mechanism).

Ulrich (1987) studied the shapes of psychometric functions, which had been generated from Allan's (1975a, 1975b), Benussi's (1913), and his own data. His results can be summarized as follows.

1. Considering $Y_{L}$ and $Y_{R}$ as distribution functions of $D_{L}$ and $D_{R}$, the skewness of $D_{L}$ (i.e., $S K_{L}$ ) is much larger than is the skewness of $D_{R}$ (i.e., $S K_{R}$ ). Moreover, $S K_{\mathrm{L}}>0$, whereas $S K_{\mathrm{R}}<0$.

2. Dispersions of $D_{L}$ and $D_{R}$ are not equal (i.e., $\left.S D_{\mathrm{L}} \neq S D_{\mathrm{R}}\right)$. There is no rule as to which of the two, $S D_{\mathrm{L}}$ or $S D_{\mathrm{R}}$, is greater.

3. The difference between the means $E\left(D_{L}\right)-E\left(D_{R}\right)$ was found to be dependent on intensity. The lower the intensity of both stimuli, the greater the difference.

4. $Y_{L}$ and $Y_{R}$ increase from 0 to 1 . However, their growth is sometimes nonmonotonous contrary to our expectation. Generally, both $Y_{\mathrm{R}}$ and $Y_{\mathrm{L}}$ have at first a local maximum and then, close to it, a local minimum. Moreover, the extremal point $Y_{\mathrm{R}}$ occurs for a slightly smaller value of $d .^{1}$

The theoretical predictions derived by Ulrich (1987) from certain versions of the general threshold model (perceptual-moment model, triggered-moment model, and some versions of attention-switching model) do not agree with the above-mentioned observations. These inconsistencies provide strong evidence against these models. 
The present paper contains the description of a new model and shows how it fits the empirical data.

\section{The Two-Stage Model}

The model to be described in this paper assumes that there are two centers/mechanisms responsible for order discrimination. The first is able to determine only whether or not both stimuli appear simultaneously. The second determines which of the two was first.

Such suggestions have previously been presented. Hirsch and Sherrick (1961) argued that perception of simultaneity is not sufficient for correct order identification. This notion suggests that the mechanism for successiveness judgment is different from that for order discrimination. Guided by this notion, Mitriani, Shekerdjiiski, and Yakimoff (1986) outlined the model in which two mechanisms worked in parallel. We want to show that a model based on their idea can account for Ulrich's (1987) observations listed in the Introduction section.

The block diagram of the model is shown in Figure 1. Two sensory channels, $x$ and $y$, are stimulated at the moments $t_{\mathrm{x}}$ and $t_{\mathrm{y}}$, respectively. In each channel, sensory messages $m_{\mathbf{x}}\left(m_{\mathbf{y}}\right)$ are conveyed along a common path to a point in the brain that is reached after a delay $\mathbf{Z}_{\mathbf{x}}\left(\mathbf{Z}_{\mathbf{y}}\right)$. From this point, information is directed to the two centers. One of them is called the simultaneity center; the other is called the order center. The simultaneity center is reached after further delay $\mathbf{L}_{s x}$ (or $\mathbf{L}_{\text {sy }}$ ); the order center is reached after $\mathbf{L}_{\text {ox }}$ (or $\mathbf{L}_{\text {oy }}$ ) milliseconds. Therefore, the simultaneity center is reached at the moment $\mathbf{A}_{\mathbf{s x}}=$ $t_{\mathrm{x}}+\mathbf{Z}_{\mathrm{x}}+\mathbf{L}_{\mathrm{sx}}$ in channel $x$ and at $\mathbf{A}_{\mathrm{sy}}=t_{\mathrm{y}}+\mathbf{Z}_{\mathrm{y}}+\mathbf{L}_{\mathrm{sy}}$ in channel $y$. The information arrives at the order center at the moment $\mathbf{A}_{\mathrm{ox}}=t_{\mathrm{x}}+\mathbf{Z}_{\mathrm{x}}+\mathbf{L}_{\mathrm{ox}}$ and $\mathbf{A}_{\mathrm{oy}}=t_{\mathrm{y}}+\mathbf{Z}_{\mathrm{y}}+\mathbf{L}_{\mathrm{oy}}$ $=t_{\mathrm{x}}+\mathbf{Z}_{\mathrm{y}}+\mathbf{L}_{\mathrm{oy}}+d$ in channels $x$ and $y$, respectively.

Let's assume that both centers work according to the triggered-moment model. Therefore, after the first signal reaches the simultaneity (order) center, a time interval lasting $\mathbf{C}_{s}\left(\mathbf{C}_{\mathrm{o}}\right)$ milliseconds is triggered. If the signal from the other channel arrives at the simultaneity center before a lapse of the interval $C_{s}$, the perceptual state " $s i$ "

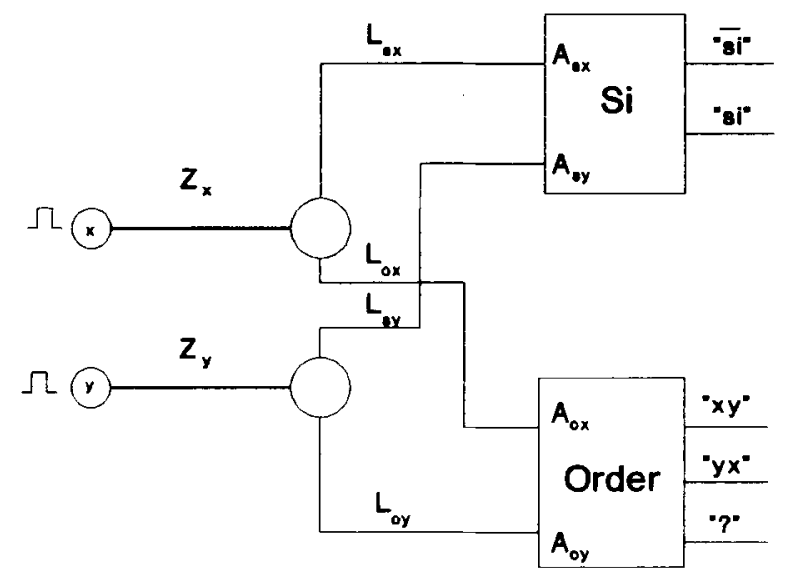

Figure 1. Block diagram of the two-stage model. Details in text. is produced. Otherwise, the perceptual state " $\overline{\mathrm{si}}$ " occurs. Thus, the condition for the perceptual state "si" appearing is $\left|\mathbf{A}_{\mathbf{s x}}-\mathbf{A}_{\text {sy }}\right|<\mathbf{C}_{\text {s. }}$.

The order center can generate three other perceptual states: " $x y$," " $y x$," and "?." The first signal reaching the order center generates the moment $C_{0}$. The state " $x y$ " ("yx") appears if $m_{\mathrm{x}}\left(m_{\mathrm{y}}\right)$ is the triggered signal and $m_{\mathrm{y}}$ $\left(m_{\mathrm{x}}\right)$ reaches the order center after the end of $\mathrm{C}_{\mathrm{o}}$; in other words, if $A_{o y} \geq A_{o x}+C_{o}\left(A_{o x} \geq A_{o y}+C_{o}\right)$. The state "?" appears if both messages $m_{\mathrm{x}}$ and $m_{\mathrm{y}}$ arrive at the order center with temporal separation lower than $C_{o}$. This is equivalent to the condition $\left|\mathbf{A}_{\text {ox }}-\mathbf{A}_{\text {oy }}\right|<\mathbf{C}_{0}$.

The subjective responses are given after examination of the perceptual states generated by both centers. The simultaneity center is examined first. If " $\mathrm{si}$ " is registered, then response $s i$ is given and the examination process is finished. Otherwise, the perceptual state generated by the order center is checked. If " $x y$ " or " $y x$ " is registered, then responses $x y$ or $y x$ are given. However, if "?" occurs, then the order of stimuli cannot be recognized properly. In such a situation, the responses are taken at random: $s i$ with probability $\alpha, x y$ with probability $\beta$, and $y x$ with probability $1-\alpha-\beta$.

Summarizing our consideration: both centers can generate five perceptual states. The conditions under which they appear are as follows:

$$
\begin{aligned}
& \text { "si": } \quad\left|\mathbf{A}_{s x}-\mathbf{A}_{s y}\right|<\mathbf{C}_{\text {s }} \\
& \text { "sisi": }\left|A_{s x}-A_{s y}\right| \geq C_{s} \\
& \text { "yx": } A_{o x}-A_{o y} \geq C_{\text {o }} \\
& \text { " } \mathrm{xy} \text { ": } \mathbf{A}_{\text {oy }}-\mathbf{A}_{\text {ox }} \geq \mathrm{C}_{\text {o }} \\
& \text { "?"': }\left|\mathbf{A}_{\text {ox }}-\mathbf{A}_{\text {oy }}\right|<\mathbf{C}_{\text {o }} \text {, }
\end{aligned}
$$

where $A_{s x}, A_{s y}, A_{o x}, A_{\text {oy }}, C_{o}$, and $C_{s}$ are assumed to be random variables.

We can write the formulas for the probabilities of subjective responses:

$$
\begin{aligned}
& Y_{\mathbf{M}}(d):=\operatorname{Pr}\{s i \mid d\}=\operatorname{Pr}\{“ s i ” \mid d\} \\
& +\alpha \cdot \operatorname{Pr}\{\text { "?" and "si " } \mid d\}
\end{aligned}
$$

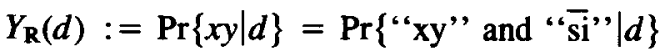

$$
\begin{aligned}
& +\beta \cdot \operatorname{Pr}\{\text { "?" and "si"' } \mid d\} \\
& Y_{\mathrm{L}}(d):=1-\operatorname{Pr}\{y x \mid d\}=1-\operatorname{Pr}\{\text { "yx" and " } \overline{\mathrm{si}} \text { "' } \mid d\} \\
& -(1-\alpha-\beta) \\
& \cdot \operatorname{Pr}\{\text { "?" and " } \overline{\mathrm{si}}, \mid d\} \text {. }
\end{aligned}
$$

\section{Fitting Empirical Data}

To show the adequacy of the model in predicting the shapes of the TOJ psychometric functions, we must introduce some additional assumptions that allow us to derive the exact formulas for $Y_{L}, Y_{R}$, and $Y_{M}$. These formulas will be fitted to the experimental data collected by Allan (1975a, 1975b) and Ulrich (1987).

1. In some models, it is assumed that central criterion is a constant value (Luce \& Green, 1972; McGill, 1963; 
McGill \& Gibbon, 1965). Although such an assumption seems to be unrealistic (cf. Grice, 1968), it works successfully. This encouraged us to assume that $\operatorname{var}\left(\mathbf{C}_{o}\right)$ and $\operatorname{var}\left(\mathbf{C}_{\mathbf{s}}\right)$ are practically equal to zero. Therefore,

$$
\mathbf{C}_{\mathrm{o}} \equiv c_{\mathrm{o}} \text { and } \mathrm{C}_{\mathrm{s}} \equiv c_{\mathrm{s}}
$$

2. Random variables $\mathbf{L}_{s x}, \mathbf{L}_{s y}, \mathbf{L}_{\mathrm{ox}}$, and $\mathbf{L}_{\mathrm{oy}}$ are normally distributed and pairwise independent. Since these variables represent latencies of sensory processes, we should have assumed that they have asymmetrical distribution. However, this assumption intensely simplifies the calculations.

3. Attempting to reduce the number of free parameters, we made some preliminary calculations. Their results revealed that the elimination of the variables $\mathbf{Z}_{\mathbf{x}}$ and $\mathbf{Z}_{\mathbf{y}}$ does not significantly worsen the goodness of fit. Because it seems to be obvious that the signals must be conveyed along a common path in the initial phases of processing, this means that the variability of $\mathbf{Z}_{\mathbf{x}}$ and $\mathbf{Z}_{\mathbf{y}}$ may be assumed to be small in respect to other sources of variability. Therefore, we will also assume that

$$
\operatorname{var}\left(\mathbf{Z}_{\mathbf{x}}\right)=\operatorname{var}\left(\mathbf{Z}_{\mathbf{y}}\right)=\mathbf{0}
$$

and that

$$
\mathrm{E}\left(\mathbf{Z}_{\mathbf{x}}-\mathbf{Z}_{\mathbf{y}}\right)=0 .
$$

This assumption also significantly simplifies calculations and reduces the number of free parameters.

Exact formulas on $Y_{M}, Y_{R}$, and $Y_{L}$ derived on the basis of the above assumptions are presented in the Appendix. Eight free parameters are involved in this formulation of the model: $c_{0}, c_{s}, \mu_{\Delta L s}, \mu_{\Delta L O}, \sigma_{\Delta L s}, \sigma_{\Delta L o}, \alpha$, and $\beta$, where $\mu_{\Delta \mathrm{L} i}$ and $\sigma_{\Delta \mathrm{L} i}$ are the mean and the standard deviation for
$\Delta \mathbf{L}_{i} \equiv \mathbf{L}_{i \mathrm{x}}-\mathbf{L}_{i \mathrm{y}}(i=\mathrm{s}, 0)$. They had to be estimated from experimental data. As it was mentioned above, we used the data obtained by Allan (1975a, 1975b) and Ulrich (1987). These studies differ as to the conditions and instructions for the subjects.

Allan (1975a), in the section devoted to successiveness/ order task of her experiment, asked the subject to determine whether $S_{\mathrm{x}}$ and $S_{\mathrm{y}}$ were simultaneous (response: $s i$ ) or successive (response: $s u$ ). The subject was then required to try to determine the order of stimuli. Thus, four responses were possible: $x y_{\mathrm{su}}, x y_{\mathrm{si}}, y x_{\mathrm{su}}$, and $y x_{\mathrm{si}}$. On the basis of these four responses, we can generate three psychometric functions corresponding to those defined by Formulas 1, 2, and 3:

$$
\begin{aligned}
& Y_{\mathrm{M}}(d)=\operatorname{Pr}\left\{x y_{\mathrm{si}} \mid d\right\}+\operatorname{Pr}\left\{y x_{\mathrm{si}} \mid d\right\} \\
& Y_{\mathrm{R}}(d)=\operatorname{Pr}\left\{x y_{\mathrm{su}} \mid d\right\} \\
& Y_{\mathrm{L}}(d)=1-\operatorname{Pr}\left\{y x_{\text {su }} \mid d\right\} .
\end{aligned}
$$

Allan (1975b) presented an experiment in which the subject rated his/her confidence concerning his/her order judgment. Four response categories were permissible: (1) "certain that $S_{x}$ proceeds $S_{y}$ " (response: $x y_{c}$ ), (2) "certain that $S_{\mathrm{y}}$ proceeds $S_{\mathrm{x}}$ " (response: $y x_{\mathrm{c}}$ ), (3) "uncertain that $S_{\mathrm{x}}$ proceeds $S_{\mathrm{y}}$ " (response: $x y_{\mathrm{uc}}$ ), and (4) "uncertain that $S_{\mathrm{y}}$ proceeds $S_{\mathrm{x}}$ " (response: $y x_{\mathrm{uc}}$ ). As was found in Allan (1975a), we can generate three psychometric func-

\begin{tabular}{|c|c|c|c|c|c|c|c|c|c|}
\hline Subject & $\mu_{\Delta L}$ & $\mu_{\Delta L_{0}}$ & $c_{3}$ & $c_{\mathrm{o}}$ & $\sigma_{\Delta \mathbf{L s}}$ & $\sigma_{\Delta \mathbf{L O}}$ & $\alpha$ & $\beta$ & $\chi^{2}$ \\
\hline \multicolumn{10}{|c|}{ Allan (1975a) } \\
\hline A.J. & 9.4 & 58.1 & 31.1 & 60.0 & 39.2 & 69.8 & 0.02 & 0.48 & 4.29 \\
\hline T.M. & 17.9 & -12.7 & 33.8 & 51.4 & 26.6 & 44.7 & 0.33 & 0.16 & 3.99 \\
\hline B.P. & 10.9 & 30.6 & 35.1 & 23.7 & 48.9 & 78.3 & 0.12 & 0.86 & 5.34 \\
\hline \multicolumn{10}{|c|}{ Allan (1975b) } \\
\hline V.R. & 18.9 & -15.9 & 25.7 & 41.8 & 32.1 & 49.8 & 0.64 & 0.24 & 4.27 \\
\hline L.M. & 24.9 & 14.7 & 17.8 & 63.3 & 55.2 & 30.6 & 0.54 & 0.34 & 2.10 \\
\hline V.V. & 20.2 & 10.6 & 18.4 & 74.7 & 49.5 & 41.1 & 0.08 & 0.54 & 4.16 \\
\hline B.M. & 22.6 & 36.2 & 56.4 & 93.1 & 51.9 & 60.5 & 0.33 & 0.49 & 4.21 \\
\hline N.C. & 16.0 & 21.4 & 27.2 & 16.0 & 21.4 & 34.0 & 1.00 & 0.00 & 11.12 \\
\hline A.T. & -61.3 & 26.4 & 11.7 & 103.8 & 32.4 & 41.1 & 0.56 & 0.29 & 3.45 \\
\hline \multicolumn{10}{|c|}{ Ulrich (1987): High Intensity } \\
\hline G.U. & 3.6 & 13.5 & 35.0 & 32.4 & 21.1 & 35.6 & 0.00 & 0.59 & 17.18 \\
\hline U.D. & -2.9 & 2.3 & 9.3 & 42.9 & 28.0 & 35.7 & 0.03 & 0.33 & 12.11 \\
\hline M.P. & 1.4 & 11.9 & 26.7 & 49.6 & 29.3 & 40.2 & 0.00 & 0.58 & 8.22 \\
\hline \multicolumn{10}{|c|}{ Ulrich (1987): Low Intensity } \\
\hline G.U. & 6.8 & 39.6 & 41.1 & 45.8 & 23.8 & 39.1 & 0.01 & 0.12 & 6.94 \\
\hline U.D. & -7.2 & 29.7 & 14.3 & 79.6 & 31.6 & 38.0 & 0.30 & 0.44 & 14.53 \\
\hline M.P. & 1.8 & 12.3 & 11.0 & 73.4 & 21.6 & 24.9 & 0.30 & 0.27 & 15.98 \\
\hline
\end{tabular}
tions determined as follows:

$$
\begin{aligned}
& Y_{\mathbf{M}}(d)=\operatorname{Pr}\left\{x y_{\mathrm{uc}} \mid d\right\}+\operatorname{Pr}\left\{y x_{\mathrm{uc}} \mid d\right\} \\
& Y_{\mathbf{R}}(d)=\operatorname{Pr}\left\{x y_{\mathrm{c}} \mid d\right\} \\
& Y_{\mathbf{L}}(d)=1-\operatorname{Pr}\left\{y x_{\mathrm{c}} \mid d\right\} .
\end{aligned}
$$

Table 1

Values of Free Parameters of the Model Evaluated for Allan's (1975a, 1975b) and Urich's (1987) Data 
In Ulrich's (1987) experiment, the subject judged the order of two short visual stimuli. Both stimuli might have been of high or low intensity. The subject was asked to say whether " $S_{\mathrm{x}}$ was presented before $S_{\mathrm{y}}$ " (response: $x y$ ), " $S_{\mathrm{y}}$ was presented before $S_{\mathrm{x}}$ " (response: $y x$ ), or "both were presented simultaneously" (response: si).

Calculations were performed by a computer, according to a fitting program. ${ }^{2}$ The computer was looking for the values of the parameters minimizing $\chi^{2}-$ sum (cf. Wickens, 1982) summed over all three curves.

\section{Results and Discussion}

Table 1 contains the estimated values of the model parameters for every set of data from Allan's (1975a, 1975b) and Ulrich's (1987) studies. In the last row, the $\chi^{2}$ value is given. Because we have $2 \times 9-8=10$ degrees of freedom, the critical value on the level of 0.05 is 18.30 . As can be seen, the obtained $\chi^{2}$ value does not reach this limit for any set of data. It means that there is no basis for rejection of the model.

None of the model parameters are given any special theoretical significance; it is somewhat impossible to draw interesting conclusions from analyzing values presented in Table 1 . However, one remark deserves our attention.

The values of probabilities $\alpha$ and $\beta$ depend on the strategy adopted by the subject when the information from

Subject A.J. (Allan 1975a)

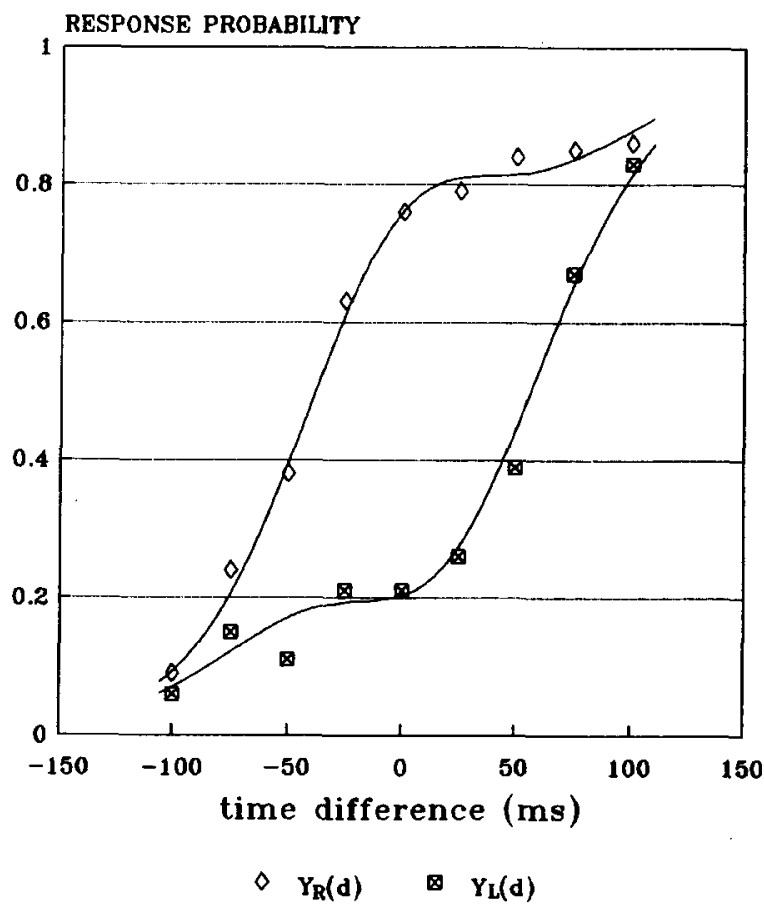

Figure 2. The psychometric functions for the ternary-response paradigm. Points are taken from Allan (1975a). The solid lines represent Formulas 1 and 2 fitted to the empirical points by the method of least squares.
Subject B.M. (Allan 1975b)

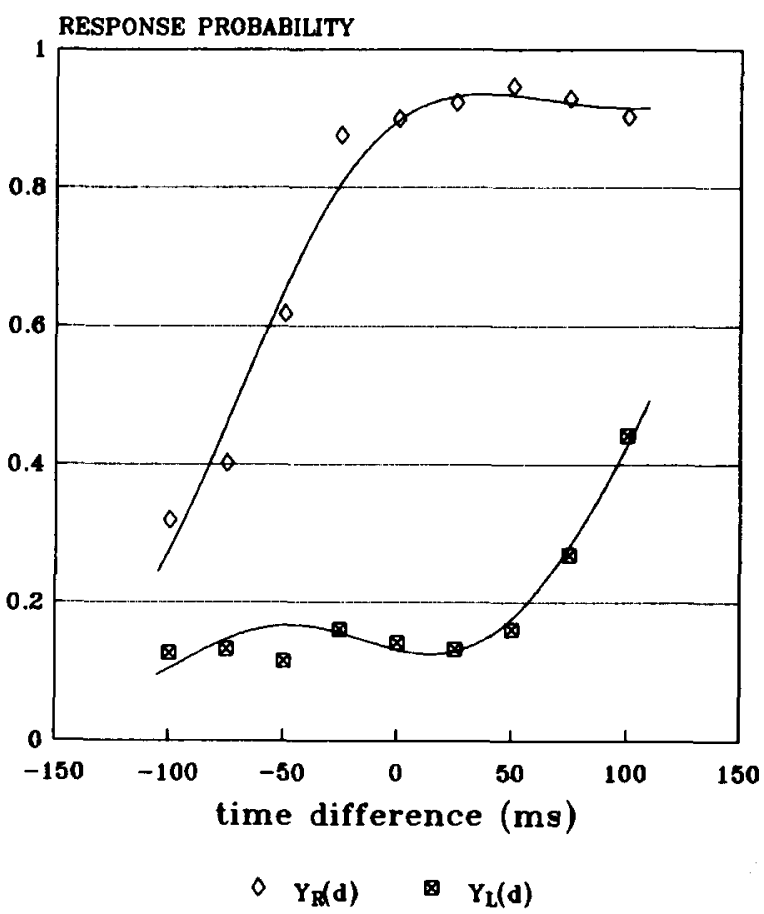

Figure 3. The psychometric functions for the ternary-response paradigm. Points are taken from Allan (1975b). The solid lines represent Formulas 1 and 2 fitted to the empirical points by the method of least squares.

both centers is not coherent. The strategy, in turn, depends on many factors connected with the experimental arrangement. The instruction for the subject is one of such factors. It seems to us that the different instructions given to the subject lead to characteristic distinctions between parameters $\alpha$ and $\beta$. According to our assumptions, uncertain responses are given when the simultaneity center reports "si," while, at the same time, their order cannot be determined by the order center. Therefore, we can expect that when the task is similar to that described in Allan's (1975a) and Ulrich's (1987) studies, the subject will avoid response si under uncertain conditions. Instead, instruction as in Allan's (1975b) study imposes the subject to answer, for example, $x y$ only when the order center reports clearly "xy," because the subject should be certain about the order. Therefore, all uncertain conditions will be classified by the subject to the si category. Consequently, we may expect an $\alpha$ value of close to zero for Allan's (1975a) and Ulrich's (1987) studies, whereas this value should be rather large for Allan's (1975b). Indeed, for six out of nine sets of data from Allan's (1975a) and Ulrich's (1987) studies, $\alpha$ was not higher than 0.1 , and for the remaining three, $\alpha$ was close to 0.3 . On the other hand, for four out of six sets of data from Allan's (1975b) study, $\alpha$ was higher than 0.3 (for Subject N.C., it was even equal to 1.0 ). 
Subject M.P. (Ulrich 1987)

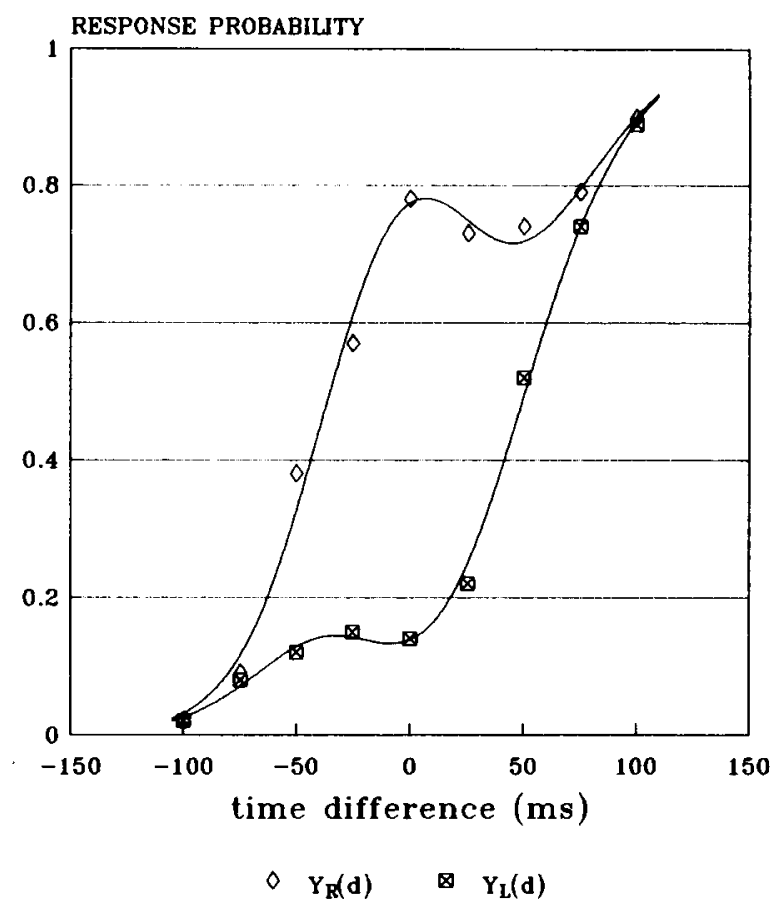

Figure 4. The poychometric functions for the ternary-response paradigm. Points are taken from Ulrich (1987, Subject M.P., high intensity). The solid lines represent Formulas 1 and 2 fitted to the empirical points by the method of least squares.
In Figures 2,3 , and 4 the exemplary curves are presented. The solid lines are the fitted curves generated from the model.

It is interesting to examine the model from the point of view of the observations made by Ulrich (1987) and summarized in the introduction of this paper. To this end, we sampled theoretical lines given by Formulas 2 and 3 for the same $d$ values as those used by Ulrich (1987) and Allan (1975a, 1975b) for each set of parameters taken from Table 1. Then, for points obtained in such a way, we calculated using the method from Ulrich's study (Spearman-Kärber method) the mean $(M)$, standard deviation $(S D)$, and skewness $(S K)$. The results are presented in Table 2. For comparison, the parameters obtained from the empirical data are also shown (they were taken from Ulrich, 1987, Table 2). As one can see, the consistency of the observed and predicted values is striking.

Now, let us consider the observations made by Ulrich:

1. $S K_{\mathrm{L}}>S K_{\mathrm{R}}$ and $S K_{\mathrm{L}}<0$, while $S K_{\mathrm{R}}>0$. This is clearly implied in Table 2.

2. The dispersion $S D_{\mathrm{L}}$ and $S D_{\mathrm{R}}$ can be different, as is shown in Table 2.

3. The model very clearly explains the shapes of psychometric functions for both intensities used by Ulrich. What is, however, surprising is the different values of $c_{\mathrm{o}}$ and $c_{s}$ for different intensities. These parameters represent some central criterion, and it is hardly conceivable that they are intensity-dependent.

Although the model is put in mathematical form, some details are not stated precisely at this time. In particular,

Table 2

Predicted and Observed Means (Ms), Standard Deviations (SD), and Skewnesses (SKs) for Allan's (1975a, 1975b) and Ulrich's (1987) Data

\begin{tabular}{|c|c|c|c|c|c|c|c|c|c|c|c|c|}
\hline \multirow[b]{2}{*}{ Subject } & \multicolumn{2}{|c|}{$M_{\mathrm{R}}$} & \multicolumn{2}{|c|}{$M_{\mathrm{L}}$} & \multicolumn{2}{|c|}{$S D_{\mathrm{R}}$} & \multicolumn{2}{|c|}{$S D_{\mathrm{L}}$} & \multicolumn{2}{|c|}{$S K_{\mathrm{R}}$} & \multicolumn{2}{|c|}{$S K_{\mathrm{L}}$} \\
\hline & Pred. & Obs. & Pred. & Obs. & Pred. & Obs. & Pred. & Obs. & Pred. & Obs. & Pred. & Obs. \\
\hline \multicolumn{13}{|c|}{ Allan (1975a) } \\
\hline A.J. & 39 & 40 & -23 & -24 & 68 & 69 & 68 & 68 & -68 & -68 & 64 & 64 \\
\hline T.M. & 53 & 53 & -35 & -36 & 53 & 51 & 54 & 53 & -64 & -60 & 54 & 55 \\
\hline B.P. & 44 & 44 & -27 & -28 & 70 & 74 & 69 & 71 & -70 & -76 & 63 & 62 \\
\hline \multicolumn{13}{|c|}{ Allan (1975b) } \\
\hline V.R. & 40 & 42 & -48 & -46 & 59 & 57 & 49 & 50 & -60 & -58 & 46 & 49 \\
\hline L.M. & 48 & 48 & -40 & -40 & 66 & 66 & 50 & 50 & -64 & -65 & 53 & 52 \\
\hline V.V. & 24 & 23 & -22 & -23 & 83 & 83 & 75 & 74 & -64 & -64 & 75 & 65 \\
\hline B.M. & 70 & 71 & -57 & -57 & 75 & 74 & 60 & 60 & -90 & -91 & 70 & 69 \\
\hline N.C. & 44 & 45 & -28 & -24 & 34 & 31 & 29 & 26 & -37 & -27 & 20 & 18 \\
\hline A.T. & 57 & 58 & -56 & -56 & 79 & 78 & 74 & 74 & -80 & -80 & 84 & 84 \\
\hline \multicolumn{13}{|c|}{ Ulrich (1987): High Intensity } \\
\hline U.D. & 1 & 2 & -20 & -20 & 57 & 56 & 54 & 53 & -31 & -30 & 46 & 46 \\
\hline M.P. & 40 & 41 & -14 & -14 & 56 & 56 & 66 & 66 & -58 & -58 & 61 & 62 \\
\hline G.U. & 47 & 47 & -26 & -28 & 37 & 36 & 46 & 46 & -43 & -44 & 56 & 56 \\
\hline \multicolumn{13}{|c|}{ Ulrich (1987): Low Intensity } \\
\hline U.D. & 65 & 65 & -3 & -3 & 66 & 64 & 84 & 84 & -77 & -72 & 61 & 63 \\
\hline M.P. & 32 & 31 & -30 & -31 & 72 & 73 & 66 & 67 & -63 & -65 & 68 & 69 \\
\hline G.U. & 49 & 49 & -35 & -36 & 42 & 41 & 42 & 42 & -49 & -49 & 53 & 53 \\
\hline
\end{tabular}

Note-Pred. $=$ predicted, Obs. $=$ observed. 
the nature of the moment-gating mechanism is not defined and requires further elaboration. We hope that the explanation of this point will be possible when more experimental data are collected.

4. The examples presented in Figures 2, 3, and 4 were chosen in such a way as to show that the psychometric functions $Y_{\mathrm{L}}$ and $Y_{\mathrm{R}}$ can be monotonous, as well as nonmonotonous. Moreover, for nonmonotonous curves, the local extremum of $Y_{R}$ occurs sooner (i.e., for the smaller value of $d$ ) than does the local extremum of $Y_{L}$.

Although the two-stage model successfully explains the shape of psychometric functions obtained in the ternaryresponse paradigm, there is no doubt that only new experiments can verify it. An interesting step in this direction was done by Ulrich, Schäffer, and Giray (1989). Using the reaction time task, they showed that the information about successiveness/simultaneity is available sooner than is the information about order. They concluded that there is something like an earlier processing stage in which it is determined whether or not the stimuli are presented in succession. Our model closely corresponds with this finding. In our model, the simultaneity and order centers do not work in series. However, it is assumed that the information from the simultaneity center is analyzed first, and the order-center report is considered only if "si" is reported by the simultaneity center. It would be interesting to explore whether the model in which both stages work in series can also account for the experimental results.

\section{REFERENCES}

Allan, L. G. (1975a). The relationship between judgment of successiveness and judgment of order. Perception \& Psychophysics, 18, 29-36.

Allan, L. G. (1975b). Temporal order psychometric functions based on confidence-rating data. Perception \& Psychophysics, 18, 369-372.

Benussi, V. (1913). Psychologie der Zeitauffassung [Psychology of the conception of time]. Heidelberg: Carl Winter's Universitätshandlung.

Grice, G. R. (1968). Stimulus intensity and response evocation. Psychological Review, 75, 359-373.

Hirsh, I. J., \& Sherrick, C. E. (1961). Perceived order in different sense modalities. Journal of Experimental Psychology, 62, 423-432.

LUCE, R. D., \& Green, D. M. (1972). A neural timing theory for response times and the psychophysics of intensity. Psychological Review, 79, 14-57.

McGiLL, W. J. (1963). Stochastic latency mechanisms. In R. D. Luce, R. R. Bush, \& E. Galanter (Eds.), Handbook of mathematical psychology (Vol. 1, pp. 309-360). New York: Wiley.

MCGILL, W. J., \& GiBBoN, J. (1965). The general gamma distribution and reaction time. Journal of Mathematical Psychology, 2, 1-18.

Mitrani, S., Shekerdjuski, S., \& Yakimoff, N. (1986). Mechanisms and asymmetries in visual perception of simultaneity and temporal order. Biological Cybernetics, 54, 159-165.

SternberG, S., \& KNolL, R. L. (1973). The perception of temporal order: Fundamental issues and a general model. In S. Kornblum (Ed.), Attention and performance IV (pp. 629-685). New York: Academic Press.

ULRICH, R. (1987). Threshold models of temporal-order judgments evaluated by a ternary response task. Perception \& Psychophysics, 42, 224-239.

UlRICH, R. (1988). Erratum to Ulrich (1987). Perception \& Psychophysics, 44, 98.

UlRich, R., SCHÄFFeR, R., \& GiRAY, M. (1989). Der Zusammenhang zwischen Wahmehmung von Ungleichzeitigkeit und Reihenfolge. Manuscript submitted for publication.

WiCKENS, T. D. (1982). Models for behavior: Stochastic processes in psychology. San Francisco: Freeman.

\section{NOTES}

1. In Ulrich's (1987) article, there is still one point regarding the socalled "dominance property." However, Ulrich (1988) showed that it is a direct consequence of the definitions of $Y_{\mathrm{L}}$ and $Y_{\mathrm{R}}$.

2. The author is indebted to Rolf Ulrich for rendering the fitting program and the program for the calculations of raw moments.

\section{APPENDIX}

$$
\text { Let } \phi\left(x, \mu, \sigma^{2}\right):=\frac{1}{\sqrt{2 n}} \cdot \int_{-\infty}^{\mathrm{x}} \exp \left(-\frac{1}{2}(x-\mu)^{2} / \sigma^{2}\right) d x
$$

Since $\mathbf{L}_{\mathrm{sx}}\left(\mathbf{L}_{\mathrm{ox}}\right)$ and $\mathbf{L}_{\mathrm{sy}}\left(\mathbf{L}_{\mathrm{oy}}\right)$ are assumed to be normally distributed and pairwise independent, then $\Delta \mathbf{L}_{\mathbf{s}}:=\mathbf{L}_{\mathbf{s x}}-\mathbf{L}_{\mathbf{s y}}$ $\left(\Delta \mathbf{L}_{\mathbf{o}}:=\mathbf{L}_{\mathbf{o x}}-\mathbf{L}_{\mathbf{o y}}\right)$ is normally distributed. Therefore, we can write

$$
\begin{aligned}
& \operatorname{Pr}\left\{\Delta \mathbf{L}_{s}<d\right\}=\phi\left(d, \mu_{\Delta \mathbf{L} s}, \sigma_{\Delta \mathbf{L} s}^{2}\right) \\
& \operatorname{Pr}\left\{\Delta \mathbf{L}_{o}<d\right\}=\phi\left(d, \mu_{\Delta \mathbf{L o}}, \sigma_{\Delta \mathbf{L o}}^{2}\right) .
\end{aligned}
$$

1. $\operatorname{Pr}\{$ "si" $\mid d\}=\operatorname{Pr}\left\{\left|\mathbf{A}_{\mathrm{sx}}-\mathbf{A}_{\mathrm{sy}}\right|<\mathbf{C}_{\mathrm{s}}\right\}$

$=\operatorname{Pr}\left\{-\mathbf{C}_{\mathrm{s}}<\mathbf{A}_{\mathrm{sx}}-\mathbf{A}_{\mathrm{sy}}<\mathbf{C}_{\mathrm{s}}\right\}$. Since $\mathbf{A}_{\mathrm{sx}}:=\mathbf{L}_{\mathrm{sx}}+t$ and

$\mathbf{A}_{\mathrm{sy}}=\mathbf{L}_{\mathrm{sy}}+d+t$, then $\mathbf{A}_{\mathbf{s x}}-\mathbf{A}_{\mathrm{sy}}=\mathbf{L}_{\mathrm{sx}}-\mathbf{L}_{\mathrm{sy}}-d=\Delta \mathbf{L}_{\mathrm{s}}-d$.

$\operatorname{Pr}\{$ "si'" $\mid d\}=\operatorname{Pr}\left\{-c_{\mathrm{s}}<\Delta \mathbf{L}_{\mathrm{s}}-d<c_{\mathrm{s}}\right\}$

$=\operatorname{Pr}\left\{-c_{\mathrm{s}}+d<\Delta \mathbf{L}_{\mathrm{s}}<c_{\mathrm{s}}+d\right\}=\phi\left(c_{\mathrm{s}}+d, \mu_{\Delta \mathbf{L s}}, \sigma_{\Delta \mathbf{L} s}^{2}\right)$

$-\phi\left(-c_{\mathrm{s}}+d, \mu_{\Delta \mathrm{Ls}}, \sigma_{\Delta \mathrm{Ls}}^{2}\right)$.

2. Since $A_{\mathrm{ox}}-\mathbf{A}_{\mathrm{oy}}=\mathbf{L}_{\mathrm{ox}}-\mathbf{L}_{\mathrm{oy}}-d$, we have

$\operatorname{Pr}\{$ "xy" and "si'" $\mid d\}=\operatorname{Pr}\left\{\left|\mathbf{A}_{\mathrm{sx}}-\mathbf{A}_{\mathrm{sy}}\right| \geq c_{\mathrm{s}}\right\}$

- $\operatorname{Pr}\left\{\mathbf{A}_{\mathrm{oy}}-\mathbf{A}_{\mathrm{ox}} \geq c_{\mathrm{o}}\right\}=\operatorname{Pr}\left\{\left|\mathbf{A}_{\mathrm{sx}}-\mathbf{A}_{\mathrm{sy}}\right| \geq c_{\mathrm{s}}\right\}$

- $\operatorname{Pr}\left\{-\Delta \mathbf{L}_{\mathrm{o}}+d \geq c_{\mathrm{o}}\right\}=\left[1-\operatorname{Pr}\left\{\left|\mathbf{A}_{\mathrm{sx}}-\mathbf{A}_{\mathrm{sy}}\right|<c_{\mathrm{s}}\right\}\right]$

- $\operatorname{Pr}\left\{\Delta \mathbf{L}_{\mathbf{o}}<d-c_{\mathbf{o}}\right\}=\left[1-\operatorname{Pr}\left\{\left|\mathbf{A}_{\mathbf{s x}}-\mathbf{A}_{\mathbf{s y}}\right|<c_{\mathbf{s}}\right\}\right]$

$\phi\left(d-c_{0}, \mu_{\Delta \mathrm{Ls}}, \sigma_{\Delta \mathrm{Lo}}^{2}\right)$. Finally, $\operatorname{Pr}\{“ \mathrm{xy} "$ and "“ii $" \mid d\}$

$=\left[1-\phi\left(c_{s}+d, \mu_{\Delta L s}, \sigma_{\Delta L s}^{2}\right)+\phi\left(-c_{s}+d, \mu_{\Delta L s}, \sigma_{\Delta L s}^{2}\right)\right]$

$\phi\left(d-c_{0}, \mu_{\Delta L 0}, \sigma_{\Delta L 0}^{2}\right)$.

3. Similarly, $\operatorname{Pr}\{$ "yx" and "sì" $\mid d\}$

$=\operatorname{Pr}\left\{\left|\mathbf{A}_{\text {sx }}-\mathbf{A}_{\text {sy }}\right| \geq c_{\mathrm{s}}\right\} \cdot \operatorname{Pr}\left\{\mathbf{A}_{\mathrm{ox}}-\mathbf{A}_{\mathrm{oy}} \geq c_{\mathrm{o}}\right\}$

$=\operatorname{Pr}\left\{\left|\mathbf{A}_{\mathrm{sx}}-\mathbf{A}_{\mathrm{sy}}\right| \geq c_{\mathrm{s}}\right\} \cdot \operatorname{Pr}\left\{\Delta \mathbf{L}_{\mathrm{o}}-d \geq c_{\mathrm{o}}\right\}$

$=\left[1-\operatorname{Pr}\left\{\left|\mathbf{A}_{\mathbf{s x}}-\mathbf{A}_{\mathbf{s y}}\right|<c_{\mathrm{s}}\right\}\right] \cdot\left[1-\operatorname{Pr}\left\{\Delta \mathbf{L}_{\mathrm{o}}<d+c_{\mathrm{o}}\right\}\right]$

$=\left[1-\operatorname{Pr}\left\{\left|\mathbf{A}_{\mathrm{sx}}-\mathbf{A}_{\mathrm{sy}}\right|<c_{\mathrm{s}}\right\}\right] \cdot\left[1-\phi\left(d+c_{\mathrm{o}}, \mu_{\Delta \mathrm{Ls}}, \sigma_{\Delta \mathrm{Lo}}^{\mathbf{2}}\right)\right]$.

Therefore, $\operatorname{Pr}\{$ " $\mathrm{yx}$ " and " $\overline{\mathrm{si}}$ "' $\mid d\}$

$=\left[1-\phi\left(c_{\mathrm{s}}+d, \mu_{\Delta \mathrm{Ls}}, \sigma_{\Delta \mathrm{Ls}}^{2}\right)+\phi\left(-c_{\mathrm{s}}+d, \mu_{\Delta \mathrm{Ls}}, \sigma_{\Delta \mathrm{Ls}}^{2}\right)\right]$

$\left[1-\phi\left(d+c_{\mathrm{o}}, \mu_{\Delta \mathrm{Lo}}, \sigma_{\Delta \mathrm{Lo}}^{2}\right)\right]$.

4. After transformations identical to those in point $\mathrm{Al}$, we have $\operatorname{Pr}\{$ "?" and "'si'" $\mid d\}=\left[1-\phi\left(c_{\mathrm{s}}+d, \mu_{\Delta \mathrm{Ls}}, \sigma_{\Delta \mathrm{Ls}}^{2}\right)\right.$

$\left.+\phi\left(-c_{\mathrm{s}}+d, \mu_{\Delta \mathrm{Ls}}, \sigma_{\Delta \mathrm{Ls}}^{2}\right)\right] \cdot\left[\phi\left(c_{\mathrm{o}}+d, \mu_{\Delta \mathrm{Lo}}, \sigma_{\Delta \mathrm{Lo}}^{2}\right)\right.$

$\left.-\phi\left(-c_{\mathrm{o}}+d, \mu_{\Delta \mathrm{Lo}}, \sigma_{\Delta \mathrm{Lo}}^{2}\right)\right]$. 


\section{GLOSSARY}

This list of symbols deals with the general threshold model and is based on Ulrich's (1987) glossary.

TOJ Temporal-order judgment.

$S_{\mathrm{x}}\left(S_{\mathrm{y}}\right) \quad$ Stimulus in channel $x(y)$.

$d$ Time difference between the presentation of $S_{\mathrm{x}}$ and $S_{\mathrm{y}}$.

$x y(y x) \quad$ Subjective report that $S_{\mathrm{x}}\left(S_{\mathrm{y}}\right)$ appears before $S_{\mathrm{y}}\left(S_{\mathrm{x}}\right)$.

si Subjective report that $S_{\mathrm{x}}$ and $S_{\mathrm{y}}$ appear simultaneously.

$Y_{\mathrm{L}}$ and $Y_{\mathrm{R}} \quad$ Psychometric functions defined as $Y_{\mathrm{L}}(d)$ $:=1-\operatorname{Pr}\{y x \mid d\}$ and $Y_{\mathbf{R}}(d):=\operatorname{Pr}\{x y \mid d\}$.

$\mathbf{L}_{\mathbf{x}}\left(\mathbf{L}_{\mathbf{y}}\right) \quad$ Arrival latency of the message elicited by $S_{\mathrm{x}}\left(S_{\mathrm{y}}\right)$ at the locus of central order mechanism.

$\mathbf{C}_{\mathrm{xy}}\left(\mathbf{C}_{\mathrm{yx}}\right)$ Threshold value assumed in the general threshold model, if the message elicited by $S_{\mathrm{x}}\left(S_{\mathrm{y}}\right)$ arrives at the central order mechanism first.

$\mathbf{D}_{\mathbf{L}}\left(\mathbf{D}_{\mathbf{R}}\right)$ Random variables defined as $\mathbf{D}_{\mathbf{L}}:=$ $L_{x}-L_{y}+C_{x y}$ and $D_{R}:=L_{x}-L_{y}-C_{y x}$.

$S D$ Estimate of the standard estimation of $\mathbf{D}$.

SK Estimate of the skewness coefficient of $\mathbf{D}$.

This list of symbols deals with the two-stage moment model.

$\mathbf{A}_{\mathbf{s x}}\left(\mathbf{A}_{\mathrm{sy}}\right)$ Arrival time of the message elicited by $S_{\mathrm{x}}$ $\left(S_{y}\right)$ at the locus of simultaneity center.

$\mathbf{A}_{\mathrm{ox}}\left(\mathbf{A}_{\mathrm{oy}}\right) \quad$ Arrival time of the message elicited by $S_{\mathrm{x}}\left(S_{\mathrm{y}}\right)$ at the locus of order center.

$\mathbf{C}_{\mathrm{s}}\left(\mathrm{C}_{\mathrm{o}}\right)$ Threshold value of the simultaneity (order) center. "si" and "si" Perceptual states generated by the simultaneity center when $\left|\mathbf{A}_{\mathbf{s x}}-\mathbf{A}_{\text {sy }}\right|<\mathbf{C}_{\mathbf{s}}$ and $\left|A_{\text {sx }}-\mathbf{A}_{\text {sy }}\right| \geq \mathbf{C}_{\text {s. }}$.

" $x y$ " and " $y x$ " Perceptual states generated by the order center when $A_{0 y} \geq C_{0}+A_{0 x}$ and $A_{\text {ox }} \geq \mathbf{C}_{0}+A_{\text {oy }}$.

"?" Perceptual state generated by the order center when $\left|\mathbf{A}_{\text {ox }}-\mathbf{A}_{\text {oy }}\right|<\mathbf{C}_{\text {o }}$.

$\alpha(\beta) \quad$ Probability of the response si $(x y)$ when the order and simultaneity centers generate the conflict reports.

$\mathbf{Z}_{\mathbf{x}}\left(\mathbf{Z}_{\mathbf{y}}\right)$ Delay after which the sensory message from channel $x(y)$ reaches the end of common path.

$\mathbf{L}_{s x}\left(\mathbf{L}_{o x}\right) \quad$ The time needed for carrying the sensory message evoked in channel $x$ from the end of common path to the simultaneity (order) center.

$\mathbf{L}_{\mathrm{sy}}\left(\mathbf{L}_{\mathrm{oy}}\right)$ The time needed for carrying the sensory message evoked in channel $y$ from the end of common path to the simultaneity (order) center.

$\Delta \mathbf{L}_{\mathrm{s}}\left(\Delta \mathbf{L}_{\mathrm{o}}\right) \quad:=\mathbf{L}_{\mathrm{sx}}-\mathbf{L}_{\mathrm{sy}}\left(\mathbf{L}_{\mathrm{ox}}-\mathbf{L}_{\mathrm{oy}}\right)$.

$\mu_{\Delta L s}\left(\mu_{\Delta L o}\right) \quad$ Mean value of the $\Delta \mathbf{L}_{s}\left(\Delta \mathbf{L}_{0}\right)$ normal distribution.

$\sigma_{\Delta L s}^{2}\left(\sigma_{\Delta L o}^{2}\right) \quad$ Variance of the $\Delta L_{s}\left(\Delta L_{0}\right)$ normal distribution.

$c_{s}\left(c_{0}\right) \quad$ Threshold value of the simultaneity (order) center when it is assumed that $\operatorname{var}\left(\mathbf{C}_{\mathrm{s}}\right)=0\left[\operatorname{var}\left(\mathbf{C}_{\mathrm{o}}\right)=0\right.$ ]

$Y_{M} \quad$ Psychometric function defined as $Y_{M}(d)$ $:=\operatorname{Pr}\{s i \mid d\}$.

(Manuscript received February 13, 1989; revision accepted for publication January 25,1991 .) 